\title{
Guidelines for trust interface design for public engagement Web GIS
}

\author{
Artemis Skarlatidou*, Tao Cheng and Muki Haklay \\ Department of Civil, Environmental and Geomatic Engineering, University College London (UCL), \\ London, UK
}

(Received 6 May 2012; final version received 24 December 2012)

\begin{abstract}
Attesting to the powerful capabilities and in technology trends, many scholars envisioned the consolidation of geographic information systems (GIS) into vital tools for disseminating spatial information. GIS are presently used to inform, advise and instruct users in several contexts and to further engage citizens in decision-making processes that can impact and sustain policy development. Interaction with these applications incorporates risk and uncertainty, which have been repeatedly identified as preconditions in nurturing trust perceptions and which instigate a user's decision to rely on a system and act on the provided information. Research studies consistently demonstrated that a trust-oriented interface design can facilitate the development of more trustworthy, mainly e-commerce, systems. Trust in the Web GIS context, despite its significance, has only relatively recently received some attention. A set of human-computer interaction (HCI) user-based studies revealed some Web GIS trustee attributes that influence nonexperts' trust beliefs and found that when these are problematic or absent from interface design, users form irrational trust perceptions, which amplifies the risk and may impose dangers to the user. These Web GIS trustee attributes that influence non-experts' trust perceptions are formulated here into a set of trust guidelines. These are then evaluated using the PE-Nuclear tool, a Web GIS application, to inform the public about the site selection of a nuclear waste repository in the United Kingdom. Our preliminary results indicate that the proposed trust guidelines not only support the development of rational trust perceptions that protect non-experts from inappropriate use of Web GIS technology but also contribute towards improving interaction with such applications of public interest issue.
\end{abstract}

Keywords: trust; human-computer interaction; GIS; public engagement; interface design

\section{Introduction}

The Internet, in particular the World Wide Web (the Web), is fast becoming an integral part of our daily lives and an essential medium for satisfying everyday needs. The Web has played a determinant role in the dramatic shift of the traditional cartographic landscape and contributed decisively towards the ubiquitousness of geospatial products (Miller 2006). The so-called 'Geospatial Web' (or GeoWeb), with its Web GIS applications, holds a prominent position in the wider sphere of cyberspace (Haklay et al. 2008). Web GIS - simply and broadly defined as the applications that allow users to browse, view and occasionally contribute geographical information and perform geospatial analysis -

\footnotetext{
*Corresponding author. Email: a.skarlatidou@ucl.ac.uk
} 
are routinely used in several contexts, from map mash-ups incorporated into a thematic diversity of Websites (Haklay et al. 2008), and public mapping applications (e.g. Google Maps) to support way finding tasks, to more advanced Web GIS applications that support different levels of public engagement in governmental decision making.

Scholars in the Public Participation GIS field have demonstrated that GIS (e.g. Carver 2001, Sieber 2006) and Web GIS (e.g. Steinmann et al. 2005) can facilitate and potentially enhance public engagement and participation in spatially related problems. Within this context, indicative examples, although we acknowledge that in their majority exemplify one-way communication, include The UK Environment Agency's What's In Your Back Yard (WIYBY) application, ${ }^{1}$ which provides information about a range of environmental issues; UK Department of Environment, Food and Rural Affairs (DEFRA) England Noise Mapping, ${ }^{2}$ which provides access to model output of urban noise; Health Profiles provided by the UK Association of Public Health Observatories ${ }^{3}$; London Metropolitan Police Crime Mapping, ${ }^{4}$ which notably crashed on its launch date due to an unexpected level of demand (i.e. 18 million hits/h) (Travis and Mulholland 2011). Undoubtedly, Web GIS have fast become major tools for the dissemination of spatial information that inform, advise and instruct users. This information and the tools that are used to make it publicly available should be usable, rational, but also trusted (Coleman and Gotze 2001, Wong and Chua 2001, Fogg 2003).

Risk and uncertainty are trust preconditions (Chopra and Wallace 2003) that are inherent to specific contexts of Web GIS use (e.g. environmental decision making), and therefore to situations in which a wrong decision to trust a Web GIS application and the information that it incorporates may have severe consequences to a user's health and financial status (e.g. incorrect assessment of flood risk which may lead into buying an inappropriate home insurance). Risk and uncertainty are further increased due to end users' limited or lack of GIS knowledge and expertise (Unwin 2005). Non-expert users may not be knowledgeable in assessing GIS or spatial data handling and accuracy issues or in assessing the correct implementation of cartographic design principles (e.g. scales and projections), which may tamper the map content with the occasional intention to misinform users (Monmonier 1996). Web GIS applications can now be created by developers who have the enthusiasm and technical knowledge (e.g. API development skills) but who at the same time lack the essential cartographic and GIS skills. Consequently, relying on the skill of the developer alone amplifies the risk and further escalates this problem. In addition, a large and growing number of studies demonstrate that there are non-expert users who have difficulty in using Web GIS applications due to specialised functionality that increases interface complexity. This differentiates Web GIS interaction from the conventional online browsing experience (Steinmann et al. 2004), but also these additional usability interaction barriers may further impact trust.

People's trust perceptions of electronic online environments influence their intentions to engage, use and accept these systems, enhance cooperative behaviour and influence the perceived user experience (Shneiderman 2000, Egger 2001, Fogg 2003). Thus, it is not surprising that, within the online context, trust has been the subject of extensive research. Studies, mainly in the e-commerce domain, have demonstrated the impact of specific trust guidelines in the design of more trustworthy systems (Shneiderman 2000, Fogg 2003). While these guidelines are useful for the e-commerce context, previous studies demonstrated that Web GIS have distinct user aspects, including the interaction with the GIS component, that influence non-experts' trust perceptions (Skarlatidou et al. 2010a, 2011a, 2011c). 
This article introduces a set of trust guidelines to improve trust in Web GIS. We start with a brief overview of online trust and its components and then briefly review a set of studies that revealed the Web GIS trustee attributes that influence non-experts' trust perceptions. These trustee attributes are used to formulate the trust guidelines presented in Section 3. Section 4 discusses the procedural framework of the evaluation experiment, and Section 5 presents the preliminary evaluation results, which show that the guidelines can assist non-experts in the development of rational trust perceptions when they interact with Web GIS. Section 6 concludes with a discussion of the findings and suggestions for future trust-based research in Web GIS.

\section{Background: online trust and trustee attributes}

Trust has been a subject of research in several disciplines and, as such, various trust definitions exist (Shapiro 1987). Despite the lack of a commonly agreed definition, specific trust components exist in any trusting relationship, which are illustrated in Figure 1. Any trusting relationship involves always two parts: a trustor and a trustee (Grabner-Kräuter and Kaluscha 2003). The trustor is a person, while the trustee may take the form of another human collaborator, an organisation or a computerised system, since humans respond socially to technology (Lee and See 2002, Fogg 2003). These two parts interact in such a way that the trustor is willing to depend on the trustee, with the confidence that the trustee will act on the trustor's best interests (Kini and Choobineh 1998). This 'willingness to depend' is the first trust precondition; if the trustor is not willing to rely on the trustee, then there is no reason to develop trust perceptions or there is distrust, a concept with different implications. Risk and uncertainty are also trust preconditions, as Trust is only needed, and actually flourishes, in an environment that is uncertain and risky (Wang and Emurian 2005, p. 111). The trustor's decision to trust and thus depend on the trustee is influenced by the trustor's propensity to trust and the trustor's trusting beliefs (cognitive

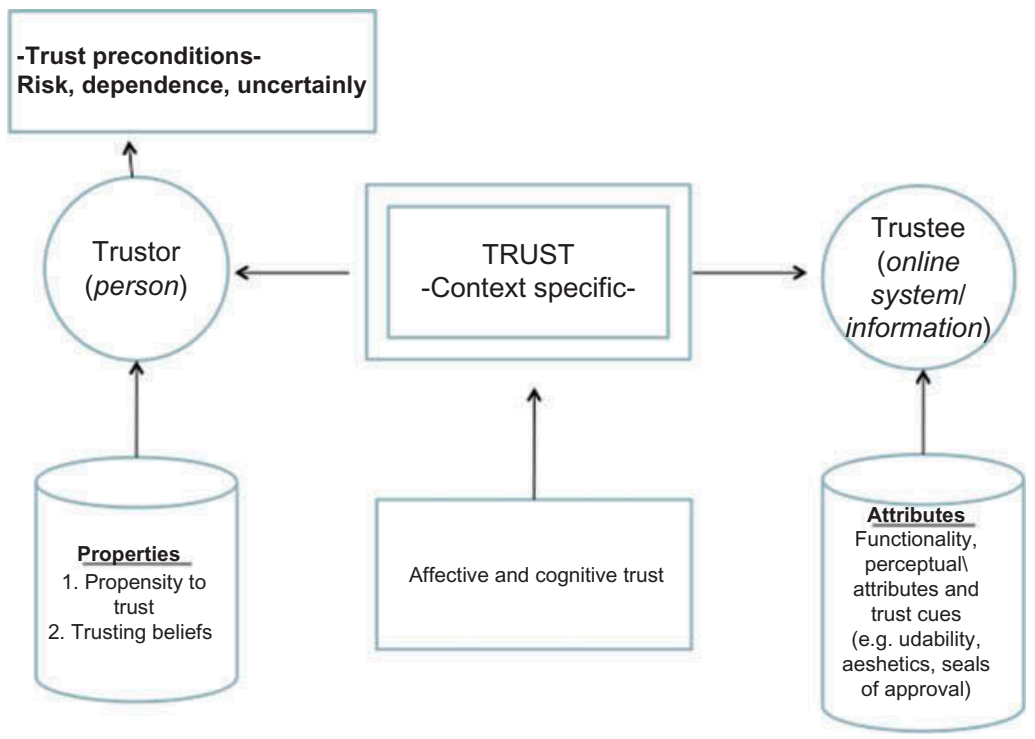

Figure 1. Trust and online trust components (Skarlatidou et al. 2011a). 
and affective) of the trustee. Trusting beliefs are influenced by the trustee attributes (e.g. the trustor's integrity and honesty if the trustor is another human collaborator).

The trustee attributes may vary according to the identity of the trustee (e.g. is the trustee a relative, a friend or a computerised system?). Particularly with respect to online trust, research in the discipline of human-computer interaction (HCI), which is concerned with the design, evaluation and implementation of interactive computing systems for human use and with the study of major phenomena surrounding them (Hewett et al. 1992, p. 6), has found that understanding the trustee attributes of a system that influence the trustor's trust perceptions can facilitate the design process of more trustworthy systems (Fung and Lee 1999, McKnight et al. 2002, Chopra and Wallace 2003, Fogg 2003, Grabner-Kräuter and Kaluscha 2003).

The trustee attributes described in the online trust literature can be differentiated between perceptual and functional. The former refers to the source and its reputation, and the latter is associated with evidence collected through interaction with the trustee and assessment of its quality (e.g. its aesthetics and usability). It should be noted that we use the term 'functional' because this category includes attributes that could be designed in such ways that improve interaction with the application (e.g. improving beauty through simplicity). A trust-oriented interface design aims at improving these attributes and also proposes the use of trust cues. Trust interface designs have been previously summarised in different sets of e-commerce trust guidelines such as those developed by Egger (2001), Fogg (2003) and Wang and Emurian (2005). Indicatively, Wang and Emurian's (2005) four-dimensional model proposes guidelines such as the use of pastel and cool tones (a functional trustee attribute that refers mainly to the Website's aesthetics), usable navigation techniques (a functional trustee attribute that refers to the Website's usability) and incorporation of interface design features that create an atmosphere of social presence (trust cues such as testimonials, chat rooms, blogs and forums).

In the Web GIS context, a set of studies recently attempted to identify the trustee attributes that influence non-experts' trust perceptions following an HCI-based, inductive research approach. Firstly, the UK Environment Agency's WIYBY application and the Spatial Decision Support System (Nuclear-SDSS ${ }^{5}$ ) 'Where to dispose of Britain's Nuclear Waste' provided by Leeds University were examined using the HCI inspection methods of Heuristic Evaluation and Cognitive Walkthrough (Skarlatidou et al. 2010a). The authors found that more than half of the general problems detected by three expert evaluators were considered as trust-related, and the majority of them were rated as critical. The detected problems unveiled the importance of specific Web GIS trustee attributes such as the use of effective menu structure and design, use of effective map colour combinations, consistency in GIS functionality and effective design and use of legends and scales that efficiently support user tasks.

The same applications were further examined using HCI empirical testing methods of Usability Testing and Cooperative Evaluation with the further involvement of 30 nonexpert users (Skarlatidou et al. 2010b, 2011b). These studies reveal that participants encountered significant problems while interacting with both applications, which resulted in a poor user experience (e.g. I was unenthused by the Website [WIYBY] and found it a bit frustrating. Probably wouldn't use it again if could avoid it; I felt frustrated and disillusioned at the end of this [for Nuclear-SDSS]); yet in their majority they stated that they trusted the applications (e.g. I would trust information coming from a government Agency on principle [for WIYBY]; Academics are probably more trustworthy as they have a degree and I believe that the system is trustworthy [for Nuclear-SDSS]). Despite the high influence of the perceptual attributes in the formation of overall trust perceptions, 
participants provided recommendations as to how specific trustee attributes should be designed to improve their trust (e.g. use of big map sizes; use of effective colour combinations to support effective map interpretation; provision of high quality and effective legends; incorporation of trust cues such as logos visible on all pages, map tutorials, blogs and external links).

To clarify the design implications of specific trustee attributes (i.e. map size, colours, scales, legends, map tutorials, use of logos and provision of data information), Skarlatidou et al. (2011c) carried out a set of additional experiments that further involved the London Air Quality Network $\left(\mathrm{LAQN}^{6}\right)$, London Profiler $\left(\mathrm{LP}^{7}\right)$ and England Noise Mapping $\left(\mathrm{ENM}^{2}\right)$ applications. It was found that non-expert participants completely ignored important trust cues (e.g. metadata) and they formed their trust perceptions purely based on interface design elements. This finding is supported by the fact that although the LAQN application updates data every two hours from monitoring sites, an important cognitive trust cue, this information was missed by participants due to ineffective design in communicating data issues. Instead, the participants showed greater levels of trust towards the LP application where the design of specific trustee attributes (e.g. map size, colours and legend) improved trustworthiness despite the fact that the data were not updated beyond the original design of the application. Amongst several recommendations, the authors suggest the use of distinct colour combinations (e.g. a red/blue/green colour scheme) that comply with basic cartographic design principles and a map size larger than $400 \times 600$ pixels, which improves readability and confidence in map interpretation and trust (as opposed to an orange/brown colour scheme and smaller map size which reduce trust).

To summarise, Web GIS trust investigations unveil the existence of specific trustee attributes that influence non-experts' trust perceptions, and suggest that when these are problematic, 'hidden' or completely absent from the interface design, non-experts tend to form rather irrational trust perceptions based on the application provider's identity or based on interface design features. These trustee attributes set the foundations for the development of a set of Web GIS trust interface design guidelines, which are discussed in Section 3. It should be noted that the proposed trust guidelines focus only on the trustee attributes that non-expert users thought are important for the formation of their trust perceptions and they derived from mainly the environmental Web GIS context.

\section{Trust guidelines}

Wang and Emurian's (2005) trust model for e-commerce is modified to accommodate the proposed Web GIS trust guidelines. The trust guidelines are organised into five design dimensions, namely, graphic, content, structure, functionality and trust cue designs. As Web GIS applications are usually integrated within Websites of a broader context and interest, the first four design dimensions propose trust guidelines separately for the Website's user interface (UI) (Appendix, Table A1) and the GIS component (Appendix, Table A2). The trust cue design dimension incorporates guidelines with respect to additional interface design elements that can be incorporated in Web GIS to improve trust.

\subsection{Graphic design}

The graphic design dimension aims at improving the graphic design quality of the UI and GIS visualisations with respect to the trustee attributes that evidently influence nonexperts' trust perceptions, such as colour combinations and map size. Specifically, these 
trust guidelines for the UI propose the use of high-quality professional graphics and also suggest that the visualisation of interface design elements should be consistent throughout the different pages of the Website. Moreover, this dimension proposes the compliance of UI design elements with Internet standards and familiar online visualisations (e.g. colour code expectations for visited links). As the GIS component adds to the complexity of these interfaces, it is essential that other UI design elements are developed considering users' prior experience with other online environments.

The graphic design guidelines for the GIS component suggest that map features and legends should be clearly communicated and that map results should stand out from base maps, while base maps should be of high quality at all provided scales and relevant to the application's context. The size of the map should be larger than $400 \times 600$ pixels, as a small map size reduces the amount of information on screen, easily giving the impression that the operator is trying to 'hide' information that further influences trust. Colour combinations should be effective so that users can interpret maps effortlessly, and to achieve this the guidelines propose the use of distinct colour combinations (e.g. red/blue/green) or alternatively the use of shades of blue, which is the second most trusted and the most preferred mapping colour combination in the study conducted by Skarlatidou et al. (2011c).

\subsection{Structure design}

The structure design dimension aims at improving the structure of the provided information to simplify navigation and promote the system's perceived transparency. The UI trust guidelines of this dimension (Table A1) suggest that information should be grouped effectively and well-structured menus should be provided for its easy identification. Textual information should be grouped effectively using headings and subheadings; hyperlinks should be used to improve the accessibility of information located on different pages. The provision of a menu item to link to the GIS component is essential to ensure that users can easily locate it; this is a feature frequently ignored by most developers.

The structure design guidelines for the GIS component (Table A2) focus on improving the trustee attributes that influence the structure of the spatial component. The guidelines propose that a legend should be always provided, even for maps considered to be simple. The legend should not block the map, hiding spatial features and giving the impression that information is intentionally 'hidden'. Finally, if the application supports user input in the form of spatial queries, then the search box should be immediately visible from the map page (ideally it should be located next to the map).

\subsection{Content design}

The accuracy and reliability of information are important in the formation of trust perceptions, yet non-experts do not always have the knowledge to assess these elements. This design dimension aims at improving specific trustee attributes, such as vocabulary used, scales provided and provision of information about data issues (Table A1), and consequently support non-experts' trust assessments with respect to the application's information content through interface design. Before presenting these guidelines, it should be noted that problem expertise is different from computer tool expertise (Nyerges 1993, p. 38), thus user expertise in the particular domain should be considered as a separate human factor from GIS expertise in influencing the application's information content. It is essential to trust that vocabulary should be easy to understand (considering users' needs 
and expectations in the specific domain) while explanations should be provided for technical and scientific terminology. Guidance and documentation explaining the application's tasks and functionality should be also provided for GIS non-experts and novice system users and error messages should be communicated in non-technical terms. In addition, the information content should satisfy the needs of novice system users but also the needs of users who use the system regularly and who, as a result of the learning curve, may develop additional needs and trust-related concerns. These should be addressed or trust may be reduced and, even worst, broken. Finally, it is essential and directly linked to trust that the information is frequently updated.

The guidelines for the GIS component in this category (Table A2) propose that information explaining map construction should be always provided; this is an important trust cue particularly when the application is used on a regular or frequent basis. Instructions and tutorials for the GIS component and provision of information about map features are also essential. Information about data issues should be also provided and should be directly visible on the map page (ideally below the map). Scale and generalisation influence ease and confidence in map interpretation and subsequently trust; according to previous trust findings, more than four scales should be provided and generalisation should not influence the required and expected level of detail and accuracy and should not complicate map interpretation.

\subsection{Functionality design}

The functionality design dimension includes guidelines that mainly focus on improving GIS functionality-related trustee attributes that influence non-experts' trust perceptions. While the application may provide various interactivity options and functions, these highly depend on contextual factors. Thus, apart from basic elements found to influence trust, such as fixing 'broken links' and 'not found pages', we do not provide further guidance on UI functionality with respect to trust, as the focus of this article is on the Web GIS trustee attributes that influence trust.

These guidelines suggest that GIS functionality should be consistent (at all scales), unique (do not provide more than one tool for the same functionality) and support task completion according to users' needs in the particular context. Functions should be predictable (i.e. tools should function as users expect) to improve the overall application's predictability which was found to influence trust (Skarlatidou et al. 2010a, 2010b, 2011b). Map tools should be easy to recognise (e.g. users are somewhat familiar with visualisations for tools such as zoom in/out functionality); if a novel tool is introduced, then a tutorial or a frequently asked questions (FAQ) section should be provided to explain how the tool works. Moreover, in the case of the Web GIS component supporting advanced functionality, a cancel or undo option should be provided to help non-experts recover from errors and handle complex tasks. Finally, the application should support different Web browsers for interacting with the GIS component; otherwise, feedback should be provided to inform users and to prevent assumptions that the GIS component is not working, which may lead to loss of trust.

\subsection{Trust cue design}

The trust cue design dimension aims to improve trust through the introduction of trustinducing features in the interface design. The proposed trust-inducing features that are incorporated in the trust cue design guidelines are summarised in Table 1. 
Table 1. Trust cue design dimension.

Trust cue design

1. The logo of the site operator or provider should be clearly visible on all pages (including the GIS component) and should be of high quality

2. Copyright and data issues (e.g. the data provider) of maps should be clearly visible (ideally below the map)

3. Provide external links for additional information

4. When external links are provided, the operators should regularly check each link provided.

Messages such as 'We are not responsible for the content' may decrease trust

5. Contact details should be easy to find (ideally as a menu item)

6. When additional services such as the 'Sign up for flood warnings' in the WIYBY example are used, it is essential to clarify how user information is treated and that it is not passed on to third parties

7. A blog that connects and creates a network of people increases trust

8. Information about data accuracy and how the maps were constructed is essential (ideally located below the map)

9. Provide a map tutorial (ideally below the map)

Previous studies reveal that features such as external links, blogs, information about map accuracy and data issues build and improve trust (Skarlatidou et al. 2010a, 2010b, 2011b). Information about data and the logos of the data providers also improve trust (Skarlatidou et al. 2010a). Although only a few of the non-expert participants thought that logos and branding influence their trust perceptions, their focus on perceptual attributes indicates otherwise (Skarlatidou et al. 2010b). Therefore, it is believed, and further supported by the evaluation results discussed in Section 5, that logos should always be existent and visible on all pages.

\section{Evaluation of trust guidelines: the nuclear waste disposal case}

The site selection process for a nuclear waste repository in the United Kingdom provides the context for the evaluation of the proposed trust guidelines, as it incorporates increased risk and uncertainty, making trust a valid research question. Moreover, the importance of Web GIS in engaging the public in this particular case study has been previously acknowledged (Evans et al. 2004). Likewise, the current Nuclear Waste Management Programme (NWMP) in the United Kingdom highlights the importance of engaging the public and providing information to improve transparency and build trust (DEFRA 2008). A Web GIS application, called Public Engagement (PE)-Nuclear tool, was developed as a proof of concept prototype for the implementation and evaluation of our trust research findings. The PE-Nuclear tool provides publicly available information on nuclear waste disposal issues (Figure 2) and a Web GIS to demonstrate the site selection criteria and the spatial effects of different weighting strategies (Figure 3).

Due to restrictions on the PE-Nuclear tool's development set by the Nuclear Decommissioning Authority (NDA), the geographical area of Cambridgeshire was chosen to illustrate the site selection process. However, it should be noted that a governmental decision has never been made proposing Cambridgeshire as a suitable area to host the repository, and the community has not expressed an interest in hosting the facility. Moreover, it should be further noted that the information content (i.e. the provided 


\section{UK Nuclear Waste Disposal}
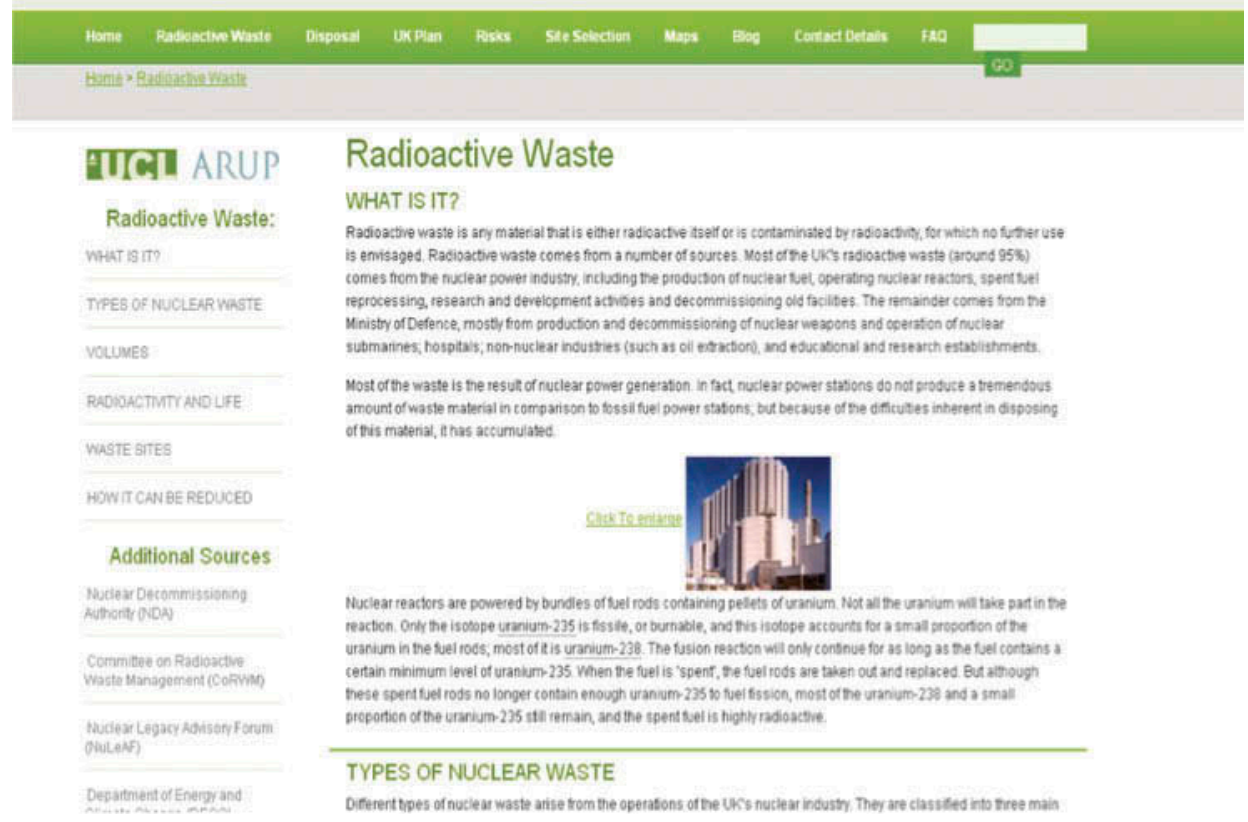

Figure 2. PE-nuclear-radioactive waste page.

information about nuclear waste, a controversial and sensitive subject which is widely discussed in the GIS and PE literature) and the structure of the PE-Nuclear tool were built using the mental models (MM) approach from the Risk Communication field (Skarlatidou et al. 2012). Using the MM approach the information content was designed in a way that (a) addresses lay people's needs with respect to what they want to know about nuclear waste and what information they expect to see on maps provided, (b) fills their knowledge gaps and (c) corrects their misconceptions. The information content on nuclear waste and its structure consisted of the subject of a separate evaluation which investigated its contribution in public knowledge and trust improvement. A further discussion of the information content's development is beyond the scope of this article. The rest of this section discusses the procedural framework for the evaluation of the trust guidelines.

The Web GIS trust investigations that we reviewed in Section 2 were based on existing applications, yet for the purpose of this evaluation experiment, it was essential to minimise any potential bias introduced by different interface designs and/or different contexts of use. To create the conditions for a controlled experiment, we first selected a set of trust guidelines from different design dimensions with respect to both the UI (e.g. information structure) and the GIS component (e.g. colours and map size). These guidelines informed the development of ten alternative interfaces of the PE-Nuclear tool. Specifically, one interface incorporated all the previously discussed trust guidelines in its interface design (Interface 1). The rest of the interfaces include the following: 


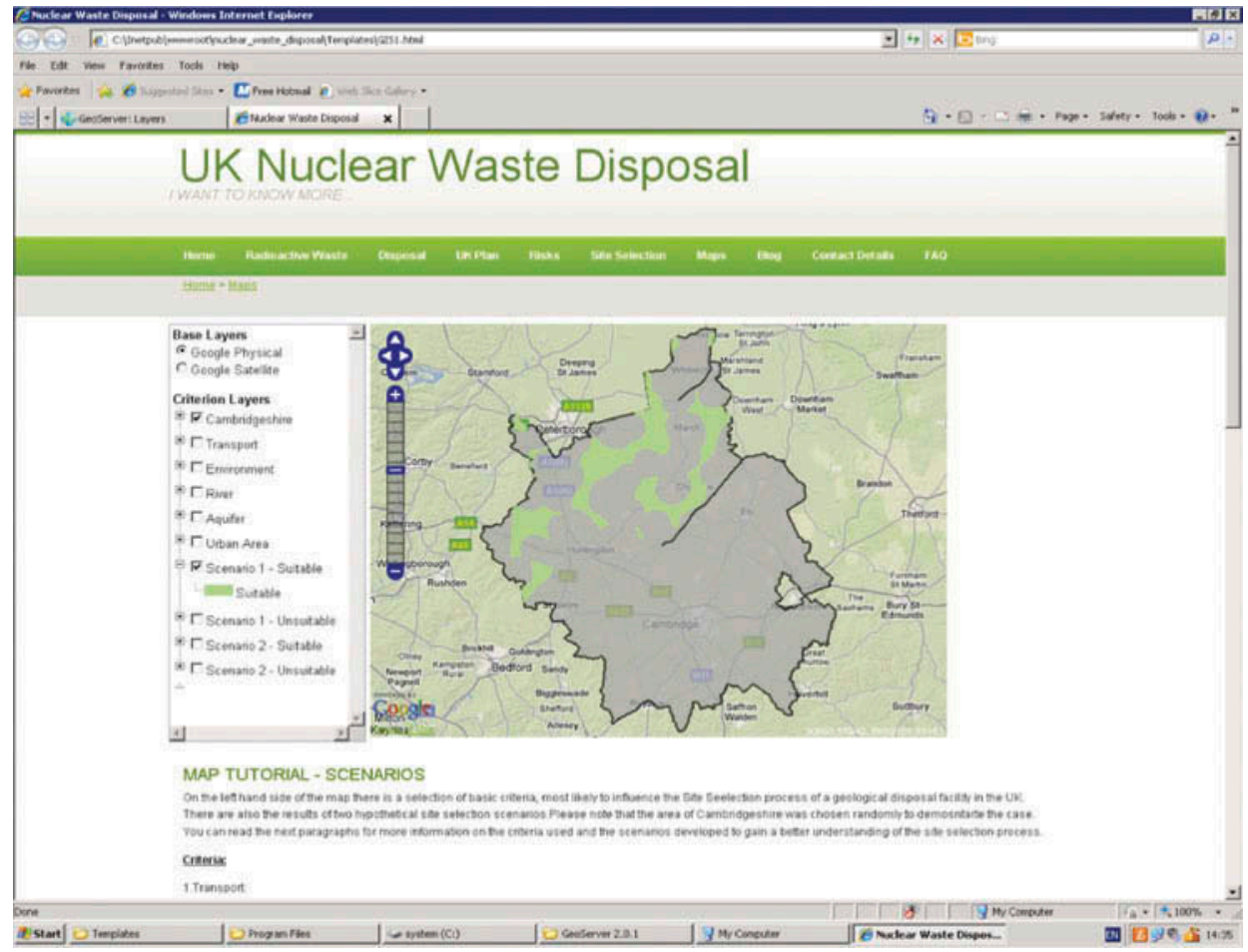

Figure 3. Suitable site for disposing of nuclear waste in Cambridgeshire.

- Interface 2: Provides different information structure (similar to Health Physics Society on Radioactive Waste Disposal Website ${ }^{8}$ ).

- Interface 3: Without logos.

- Interface 4: Without a blog and external links.

- Interface 5: Without a legend.

- Interface 6: Different map colour scheme. While all the other interfaces provide a map with distinct colour combinations, this interface provides a map using the orange/brown colour scheme, which was previously shown to be the least trusted colour combination (Skarlatidou et al. 2011c).

- Interface 7: Provides a smaller map of $362 \times 276$ pixels, which according to previous investigations was the least trusted map size (Skarlatidou et al. 2011c).

- Interface 8: Without map tutorial.

- Interface 9: Incorporates all trust guidelines and further provides a static map demonstrating the suitability of Cambridgeshire to host the repository compared to other areas in the United Kingdom using geology, indices of deprivation and location of nuclear power reactors as indicative criteria.

- Interface 10: Without information about data issues.

The aim of this evaluation is twofold. Firstly, we aimed to investigate whether the interfaces that incorporated all trust guidelines (Interfaces 1 and 9) are the most trusted, and thus whether the trust guidelines have the potential to improve trust. Secondly, we wanted to understand whether non-expert users notice the design differences of the provided interfaces and whether this influences their trust perceptions. 
Table 2. Post-test questionnaire used to evaluate trust-oriented interface design: example of legend item.

\begin{tabular}{|c|c|c|c|}
\hline \multicolumn{4}{|c|}{ Legend item } \\
\hline $\begin{array}{l}\text { How influential is the } \\
\text { legend on your } \\
\text { decision to trust an } \\
\text { online map? }\end{array}$ & $\begin{array}{l}\text { Which one of the } \\
\text { two interfaces do } \\
\text { you like the most? }\end{array}$ & $\begin{array}{l}\text { Which one of the } \\
\text { two interfaces do } \\
\text { you trust the most? }\end{array}$ & $\begin{array}{c}\text { Please make any } \\
\text { suggestions/comments }\end{array}$ \\
\hline $\begin{array}{l}\text { 1. Not at all } \\
\text { 2. Relatively important } \\
\text { 3. Very important }\end{array}$ & $\begin{array}{l}\text { Interface } 1 \\
\text { Interface } 5\end{array}$ & $\begin{array}{l}\text { Interface } 1 \\
\text { Interface } 5\end{array}$ & \\
\hline
\end{tabular}

For the evaluation experiments, a desktop computer with a 24 " monitor display was used and the experiments consisted of two stages (affective and cognitive trust stages). Firstly, a pre-test questionnaire was completed by all participants to gather information about their age, education level, frequency of Internet and Web mapping use and prior GIS knowledge to ensure that only non-experts participated in the study. Secondly, in the affective trust stage, the participants' affective responses to each interface were investigated. This involved showing each interface to the participants for $2 \mathrm{~min}$, with a 3-min break before the next interface was shown, in order to let any emotional response subside considering that emotions have a short duration of seconds to minutes (Zimmermann et al. 2003). The participants were asked to indicate how much they trusted and liked each interface using a scale from 1 (don't like/trust) to 10 (absolutely like/trust). The interfaces were shown to each participant in a different order.

In the cognitive trust stage, participants were asked to interact with each interface for $10 \mathrm{~min}$, as cognitive trust is knowledge-driven and is based on a search for evidence, or else assessment of the trustee attributes and $10 \mathrm{~min}$ was considered to be enough time for interacting with a single Web page (Riegelsberger et al. 2003). The interfaces at this stage were again provided in a different order amongst participants to counterbalance the effect of practice. For each new interface shown, they also had access to the previous interfaces so that they could comparatively assess them. All participants were asked to think aloud and express any trust concerns they had with respect to each interface and also to rate how much they trusted and liked each interface using a scale from 1 (don't like/trust) to 10 (absolutely like/trust). After interacting with all interfaces, the participants were asked to comment on the importance of each trust guideline. Table 2 demonstrates this question using the legend example (first column). Participants were shown the interface designed based on all guidelines (Interface 1) and the alternative interface where the specific guideline was absent, and they were asked to explain which one they prefer in terms of trust and which one they like the most (Table 2 - second and third columns). Finally, participants were asked to provide their suggestions and comments.

\section{Results}

To control any potential bias introduced by the recruitment of different participants who may have different propensities to trust, we decided that the same participants should be involved in both experimental stages. This resulted in a dramatic increase in the time required to run each experiment. With each experiment being $2 \mathrm{~h}$ long, the number of volunteering subjects was limited. Only ten subjects finally participated in our study to ensure that the interfaces were shown in a different order to all participants at least once. 
Participants were mainly students from different disciplines with an age range of 19-29 (average $=24$; mode $=23$ ). They all used the Internet on a daily basis, and most of them $(8 / 10)$ were frequent Web mapping users on a weekly basis, while none of the participants had a GIS educational background or any professional GIS and domain (i.e. nuclear waste) expertise.

Figure 4 summarises the affective trust stage findings. Interface 1, which incorporated all guidelines, scored second at this stage. Interface 9, which provided all guidelines as well as the national scale map demonstrating the suitability of Cambridgeshire compared to other areas in the United Kingdom, scored first. The interface that incorporated all guidelines but did not feature logos came third (mode value) together with the interfaces that did not feature a map tutorial, a blog and external links, which means that participants either did not notice the absence of the specific trust guidelines or that they noticed their absence, but this did not influence their affective trust dramatically. The interface that featured no legend and the interface using a different structure scored the lowest in terms of affective trust.

Figure 5 summarises the affective trust stage with respect to how much participants liked each interface. Interface 1, which was designed based on all trust guidelines, was the most popular interface (based on average value). The second most preferred interface was the interface that provided the national scale map as well as all other guidelines (Interface 9). The least popular interfaces included the interface that did not provide any information about the data used and the interface that had a different structure.

In the cognitive trust stage, when participants interacted with each interface, they noticed and commented on the absence of specific guidelines. For example, all participants criticised the absence of logos, the lack of information about data issues and the interface with the different information structure. Upon completion of the cognitive trust stage, all participants stated that they placed most trust in the interface that incorporated all guidelines, including the national scale map (Interface 9). Thus, this interface was the most trusted in both the affective and cognitive trust stages.

In their think-aloud comments, participants explained that the national scale map demonstrating the suitability of Cambridgeshire has the potential to improve transparency and confidence in the site selection process. It should be noted that the NWMP in the

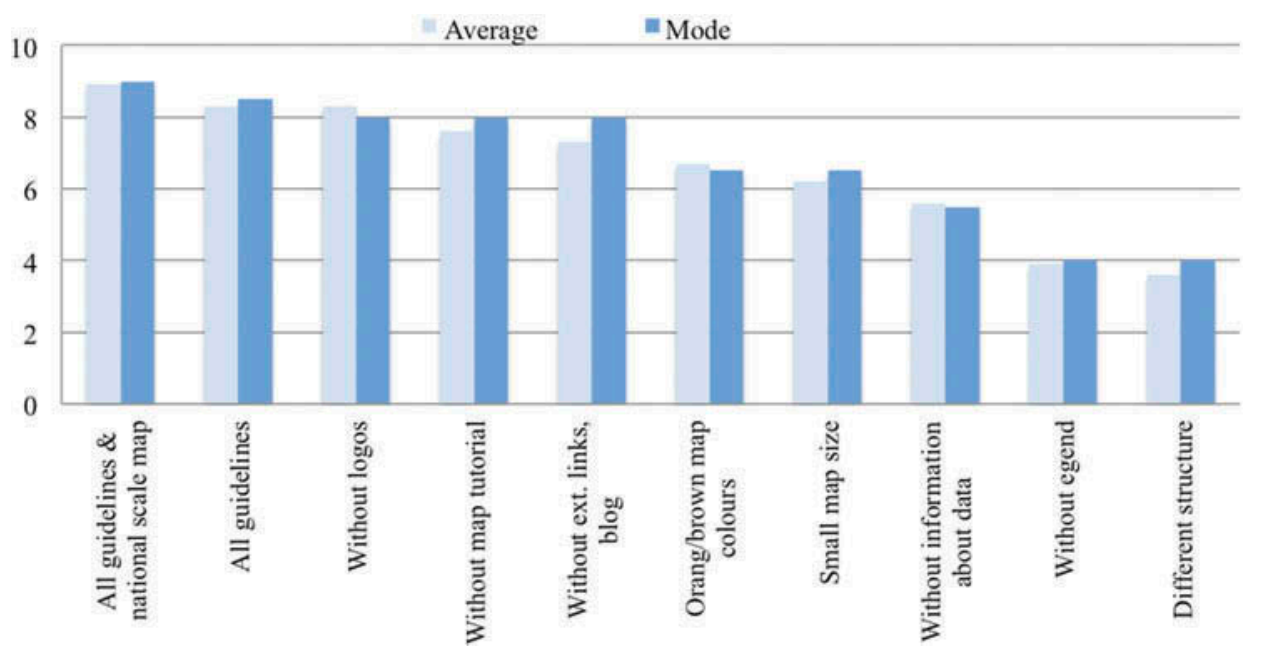

Figure 4. Participants' most and least trusted interfaces (affective trust stage). 


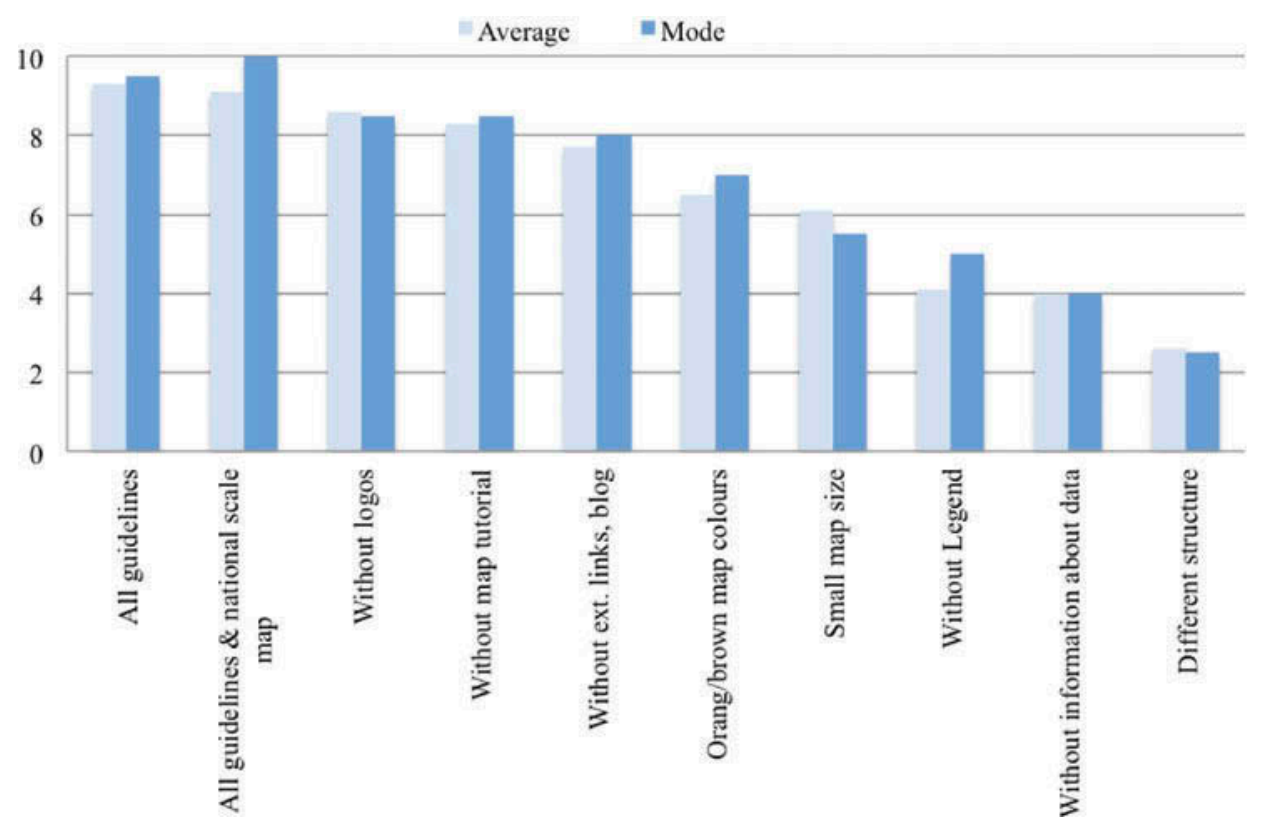

Figure 5. Participants' most and least liked interfaces (affective trust stage).

United Kingdom does not involve an initial screening out of unsuitable areas at a national level; instead, the site selection process will be only undertaken within the administrative boundaries of the communities that expressed an interest in hosting the repository (DEFRA 2008). Based on our findings, and as previously suggested (Hardy and Evans 2007, House of Lords 2007), the government should reconsider this decision, as providing national scale maps to demonstrate the suitability of an area to undergo the site selection process within its administrative boundaries may improve public trust.

The cognitive trust stage further revealed that Interface 1, which incorporated all guidelines, was the second most trusted and the most liked interface. At the end of the cognitive trust stage, the participants were informed of the design implications of each alternative interface in order to effectively comment on the importance of the specific guidelines. Figure 6 summarises these responses. It should be noted that the participants were asked to comment separately on the importance of a blog and external links despite their absence being examined through only one interface.

As Figure 6 illustrates, all participants admitted the importance of providing a legend (It is impossible to understand a map without a legend). Nine of the ten participants thought that providing information about data and a bigger map size are also very important trustee attributes (A bigger map size allows for a better visual interface and it makes me feel like I trust it more). Providing more than four scales was also considered a very important trustee attribute by eight of the ten participants. The interface with the different structure, which was the least liked during both experimental stages, was criticised as being confusing, boring and useless. Thus, the structure was also considered to be a very important trustee attribute by eight of the ten participants. Seven participants thought that colour is a very important trustee attribute before trusting a map. Only one participant thought that it is not important, yet this participant mentioned I like the colours of this interface (orange/brown map) because they appear more relaxing. On the other hand, other participants criticised 


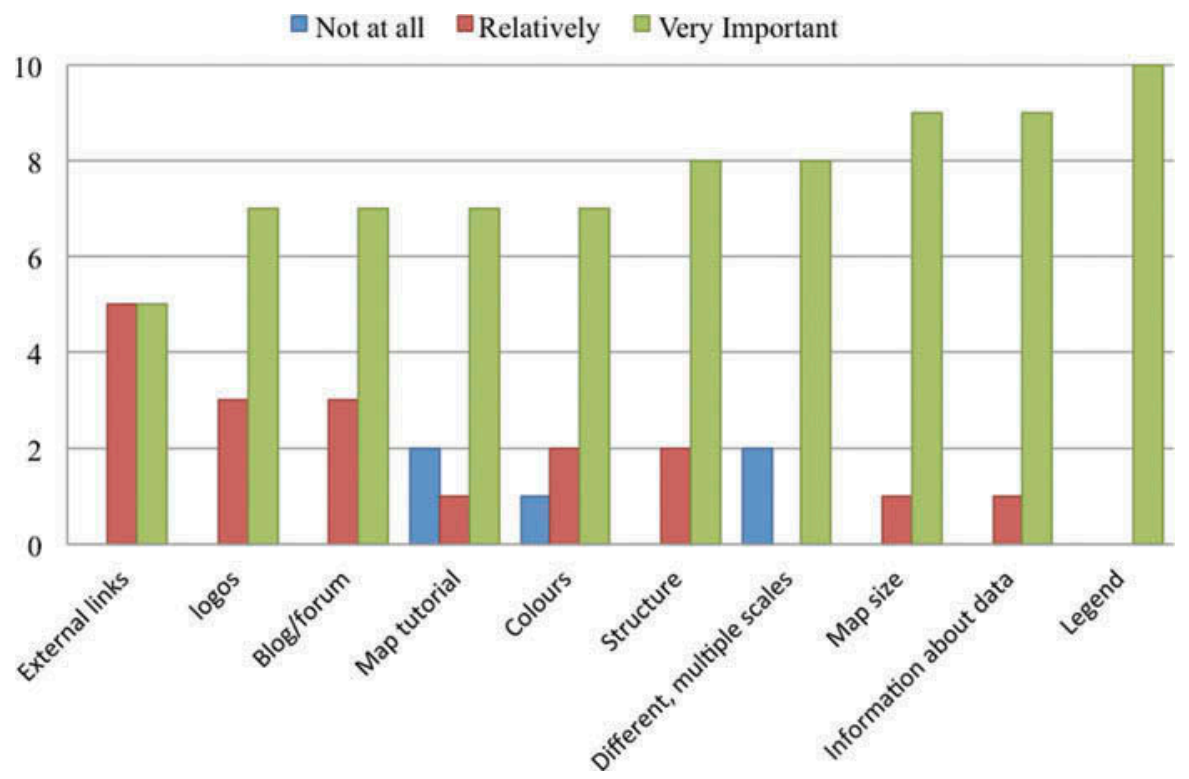

Figure 6. Relative importance of trustee attributes.

the orange/brown map (These colours are not what people usually expect to see on a map; It looks unprofessional and I would not trust it).

With respect to map tutorials, which in the case of the PE-Nuclear tool are used to explain the spatial scenarios, all participants commented that these helped them to understand the maps and seven out of ten thought that it is an important trustee attribute. Five of ten participants thought that the existence of external links is relatively important and another five thought that it is very important. Interestingly, seven of ten participants thought that the existence of logos is very important, although all of them criticised their absence in the cognitive trust stage, despite the fact that the interface that provided no logos scored third for affective trust.

\section{Summary and conclusions}

Several scholars highlight the importance of trust in the online context. Existing HCI-based studies demonstrate that there are specific trustee attributes which are assessed by end users and provide further evidence that a trust-oriented interface design that aims at improving these trustee attributes can potentially improve users' trust and confidence in using and mainly relying on the application, thus minimising the risk undertaken by the user.

User aspects (e.g. usability) in GIS and Web GIS contexts have been repeatedly identified as factors influencing interaction with these systems. In addition, there are specific Web GIS contexts of use that incorporate risk and uncertainty (e.g. Web GIS applications which engage the public and provide information to support environmental decision making) where a wrong decision to rely on them may have undesirable, or even catastrophic, consequences for end users. Despite the importance of trust in Web GIS, only recently a set of studies examined trust as a user experience aspect that influences interaction with Web GIS and revealed a set of trustee attributes that influence non-experts' trust perceptions. These trustee attributes herein are formulated into a set of trust interface design guidelines, which have five dimensions: graphic, structure, content, functionality and trust cue designs. 
The first four dimensions focus on improving the quality of specific trustee attributes of the GIS component and the rest of the application's user interface. For example, the graphic design dimension suggests improving the graphic quality and visualisation of pictures, menus and visited links and the quality of provided maps and legends. Similarly, the structure and content design dimensions refer to trustee attributes that influence the structure and content of the GIS component and the rest of the user interface. The functionality design dimension includes guidelines that refer mainly to the GIS component, such as the use of consistent, unique, easy to recognise and simple to use map functionality. Finally, the trust cue design dimension suggests trust-inducing features that can be used in Web GIS such as providing information about spatial data and map construction issues, and also external links and blogs.

To evaluate the proposed trust guidelines, we used the case of the site selection of a nuclear waste repository in the United Kingdom, as the previous ineffective attempts to locate a nuclear waste repository in the United Kingdom were mainly attributed to a loss of public trust and lack of public understanding on nuclear waste issues (Jacob 1990, Dantico and Mushkatel 1991). While the PE-Nuclear tool has the potential to advance public involvement, it is essential that it is trusted by the end users. Our preliminary (i.e. due to the nature of the experimental approach and the subsequent small population sample) evaluation results demonstrate that non-expert users have the ability to identify trustee attributes and trust cues that are important in the formation of their trust perceptions, if these are incorporated in the application's interface design. This is particularly important considering that as Harvey (2003) previously noted Trust can be rational or irrational (p. 30), and there is already evidence from previous studies that if these trustee attributes are not existent or problematic non-experts develop irrational trust perceptions based on elements such as who provides the application or based on unreasonable assumptions that due to its complexity it should be trustworthy (Skarlatidou 2012).

This is particularly problematic considering that the only trust cue that is not affectively processed is the logo of the source provider, which means that non-experts may interact with applications of unknown providers, thereby increasing the risk and the consequences that this decision may have. Another finding that highlights the significance of the proposed trust guidelines is that, unlike logos, trustee attributes such as information structure influence affective trust more than cognitive trust, which means that non-experts may decide against using a system at all if its structure is not trusted and/or liked. It may thus be concluded that improving trust in Web GIS through interface design can not only improve the overall user experience but can also help users make a confident decision as to whether they want to take any action based on the provided information.

Although the proposed trust guidelines aim to improve specific usability and aesthetical problems that influence trust, they should not be confused with cartographic design principles for effective communication, usability guidelines or guidelines that aim to improve aesthetics. For example, usability guidelines suggest that information about data accuracy should be provided (Nivala et al. 2008), yet simply providing this information is not enough. According to the proposed trust guidelines, this information should be directly visible on the map page, ideally located below the map. Another usability guideline suggests that colours should be in harmony (Nivala et al. 2008), yet based on our trust guidelines, distinct colour combinations (or shades of blue) should be used to improve trust. Similarly, it has been previously demonstrated, and also supported by our evaluation findings, that the most liked interface design elements are not necessarily the most trusted (Skarlatidou et al. 2011c) neither the most usable (Hornbaek et al. 2002). This contradicts the findings of previous studies which suggest that beautiful interfaces (or people) are perceived as trustworthy (Dion et al. 1972, Fung and Lee 1999). 
It is believed that discussions such as mystery roads . . . and how to drive from China to Japan on Google Maps (Capriotti 2010) and errors on crime maps for public use (Dominiczak et al. 2011) will influence people's propensity to trust Web GIS and their beliefs about these applications. Apart from the general observation, based mainly on the widespread use of Web GIS applications, that people have some faith in them, further research is required to understand the characteristics of different trust propensities and their influence in the formation of people's trust perceptions. Moreover, further research is required to extend the proposed trust-oriented interface design to other Web GIS contexts of use, such as crime and health where there is also a need to rely on these systems and where there is also risk and uncertainty. Such an investigation would not only support the identification of possibly additional trustee attributes but could also provide the basis for evaluating the trust guidelines using a wider population sample of non-expert users. Future investigations should be extended to include additional forms of visualisation (e.g. graphs, charts and maps viewed on 3D and even 4D displays) which may have different trust implications for non-experts users.

Finally, our findings reveal the obligation of the GIS research community and Web GIS developers to identify ways for the dissemination of spatial information that focus on protecting end users from improperly relying on incorrect or misleading information. It should be clear by now that the proposed trust guidelines suggest the improvement of trustee attributes, as these are identified by mainly non-expert users. It is not our intention to devalue the importance of research that emphasises on data accuracy, metadata and visualisation of data quality issues (e.g. Fisher 1993, 1994, MacEachren et al. 2005) and which may also influence trust and thus should be also considered by Web GIS developers. Yet as previous studies have already demonstrated the significance of such issues as 'fitness for use' and 'appropriateness of data' (Duckham 2002), we believe that the proposed trust guidelines have the potential to improve, as a user-oriented approach, non-expert interaction with GIS representations of public interest issue.

\section{Acknowledgements}

This work was funded by the Engineering and Physical Sciences Research Council (EPSRC) Doctoral Prize scheme.

\section{Notes}

1. http://maps.environment-agency.gov.uk/wiyby/wiybyController?ep=maptopics\&lang=e

2. http://services.defra.gov.uk/wps/portal/noise

3. http://www.apho.org.uk/default.aspx?QN=P_HEALTH_PROFILES

4. http://maps.met.police.uk/

5. http://www.ccg.leeds.ac.uk/teaching/nuclearwaste/

6. http://www.londonair.org.uk/london/asp/default.asp

7. http://www.londonprofiler.org/

8. http://hps.org/publicinformation/ate/cat29.html

\section{References}

Capriotti, B., 12 October 2010. Do you trust Google maps to get you there? Mystery roads, the slowest routes and how to drive from China to Japan. The Philly Post [online]. Available from: http://blogs.phillymag.com/the_philly_post/2010/12/10/do-you-trust-google-maps-to-getyou-there/ [Accessed 25 November 2010]. 
Carver, S., 2001. The future of participatory approaches using geographic information: developing a research agenda for the 21st century. URISA Journal, 15 (1), 61-71.

Chopra, K. and Wallace, W.A., 2003. Trust in electronic environments. In: Proceedings of the 36th annual Hawaii international conference on system sciences, 6-9 January 2003, Hawaii, USA, 331-340.

Coleman, S. and Gøtze, J., 2001. Bowling together: online public engagement in policy deliberation [online]. Available from: http://www.acteurspublics.com/files/epublic/pdf/scoleman-jgotzebowling-together.pdf [Accessed 28 Jan 2013]

Dantico, M.K. and Mushkatel, A.H., 1991. Public opposition to the siting of the high-level nuclear waste repository: the importance of trust. Policy Studies Review, 10 (4), 180-194.

DEFRA - Department for Environment, Food and Rural Affairs, 2008. Managing radioactive waste safely: a framework for implementing geological disposal. A White Paper by DEFRA, BERR and the devolved administrations for Wales and Northern Ireland (CM 7386). London: TSO.

Dion, K., Berscheid, E., and Walster, E., 1972. What is beautiful is good. Journal of Personality and Social Psychology, 24, 285-290.

Dominiczak, P. and Parsons, R., 2 February 2011. Anger on the quiet streets that website branded crime hotspots. Evening Standard, 25.

Duckham, M., 2002. A user-oriented perspective of error-sensitive GIS development. Transactions in GIS, 6 (2), 179-193.

Egger, F.N., 2001. Affective design of e-commerce user interface: how to maximize perceived trustworthiness. In: Proceedings of the international conference on affective human factors design, 27-29 June 2001, Singapore, 317-324.

Evans, A., Kingston, R. and Carver, S. 2004. Democratic input into the nuclear waste disposal problem: the influence of geographical data on decision making examined through a Web-based GIS. Journal of Geographical Systems, 6 (3), 117-132.

Fisher, P., 1993. Visualising uncertainty in soil maps by animation. Cartographica, 30, 20-27.

Fisher, P., 1994. Hearing the reliability in classified remotely sensed images. Cartography and Geographic Information Systems, 21, 31-36.

Fogg, B.J., 2003. Persuasive technology: using computers to change what we think and do. San Francisco, CA: Morgan Kaufmann.

Fung, R.K. and Lee, M.K., 1999. EC-trust (trust in electronic commerce): exploring the antecedent factors. In: W.D. Haseman and D.L. Nazareth, eds. Proceedings of the fifth American conference on information systems, 3-15 August 1999, Milwaukee, USA, 517-519.

Grabner- Kräuter, S. and Kaluscha, E.A., 2003. Empirical research in on-line trust: a review and critical assessment. International Journal of Human-Computer Studies, 58 (6), 783-812.

Haklay, M., Singleton, A., and Parker, C., 2008. Web mapping 2.0: the neogeography of the GeoWeb. Geography Compass, 2 (6), 2011-2039.

Hardy, J. and Evans, N., 2007. UK long term nuclear waste management: next steps? A report of the Loughborough University workshop. Loughborough University, UK, 6-7 November 2006. Loughborough: Victoire Cambridge Printers.

Harvey, F., 2003. Developing geographic information infrastructures for local government: the role of trust. Canadian Geographer, 47 (1), 28-36.

Hewett, T.T., et al., eds., 1992. ACM SIGCHI curriculum for human-computer interaction. New York: ACM.

Hornbaek, K., Bederson, B., and Plaisant, C., 2002. Navigation patterns and usability of zoomable user interfaces with and without an overview. ACM Transactions on Computer-Human Interaction, 9 (4), 362-389.

House of Lords, 2007. Radioactive waste management: an update. Report with evidence. Science and Technology Committee (HL Paper 109). London: TSO.

Jacob, G., 1990. Site unseen: the politics of siting a nuclear waste repository. PA: University of Pittsburgh Press.

Kini, A. and Choobineh, J., 1998. Trust in electronic commerce: definition and theoretical considerations. In: Proceedings of 31st Hawaii international conference on system sciences, 06-09 January 1998, 4, Kohala Coast, 51-61.

Lee, J.D. and See, K.A., 2002. Trust in computer technology and the implications for design and evaluation. In: C. Miller, ed. Etiquette for human-computer work: technical report (FS-02-02). Menlo Park, CA: American Association for Artificial Intelligence, 20-25. 
MacEachren, A., et al., 2005. Visualizing geospatial information uncertainty: what we know and what we need to know. Cartography and Geographic Information Science, 32 (3), 139-160.

McKnight, D.H., Choudhury, V., and Kacmar, C., 2002. The impact of initial trust on intentions to transact with a website: a trust building model. Journal of Strategic Information Systems, 11 (3-4), 297-323.

Miller, C., 2006. A beast in the field: the Google maps mashup as GIS. Cartographica, 41, 187-199.

Monmonier, M., 1996. How to lie with maps. Chicago and London: The University of Chicago Press.

Nivala, A.M., Brewster, S., and Sarjakoski, L.T., 2008. Usability evaluation on web mapping sites. The Cartographic Journal, 45 (2), 129-138.

Nyerges, T.L., 1993. How do people use geographical information systems? In: D. MedyckyjScott and H.M. Hearnshaw, eds. Human factors in geographical information systems. London: Bellhaven Press, 37-50.

Riegelsberger, J., Sasse, M.A., and McCarthy, J.D., 2003. Shiny, happy people building trust? Photos on e-commerce websites and consumer trust. In: Proceedings of CHI'03, human factors in computing systems, 121-128.

Shapiro, S.P., 1987. The social control of impersonal trust. American Journal of Sociology, 93 (3), $623-658$

Shneiderman, B., 2000. Designing trust into online experiences. Communication of the ACM, 43 (12), 57-59.

Sieber, R., 2006. Public participation geographic information systems: a literature review and framework. Annals of the Association of American Geographers, 96 (3), 491-507.

Skarlatidou, A., 2012. Trust in web geographical information systems for public engagement. Unpublished Eng.D. Thesis. University College London.

Skarlatidou, A., Cheng, T., and Haklay, M., 2012. What do lay people want to know about the disposal of nuclear waste? A mental model approach to the design and development of an online risk communication. Journal of Risk Analysis, 32 (9), 1496-1511.

Skarlatidou, A., Haklay, M., and Cheng, T., 2010a. Preliminary investigation of Web GIS trust: the example of the 'WIYBY' website. In: Proceedings of joint international conference on theory, data handling and modelling in geospatial information science, 26-28 May 2010, Hong Kong.

Skarlatidou, A., et al., 2010b. Trust in Web GIS: a preliminary investigation of the environment agency's WIYBY website with non-expert users. In: Proceedings of the 18th annual conference of GIS research, 14-16 April 2010, London, UK, 439-446.

Skarlatidou, A., Haklay, M., and Cheng, T., 2011a. Trust in Web GIS: the role of the trustee attributes in the design of trustworthy Web GIS applications. International Journal of GIScience, 25 (12), 1913-1930.

Skarlatidou, A., et al., 2011b. Investigating non-experts trust perceptions in spatial decision support systems for public use. In: Association of American Geographers Annual Meeting. Seattle, 12-15 April 2011.

Skarlatidou, A., et al., 2011c. Understanding the influence of specific Web GIS attributes in the formation of non-experts' trust perceptions. In: Advances in cartography and GIScience selection from ICC 2011. Paris: Springer, 219-238.

Steinmann, R., Krek, A., and Blaschke, T., 2004. Analysis of online public participatory GIS applications with respect to the differences between the US and Europe. In: 24th urban data management symposium, 27-29 October 2004, Venice, Italy.

Steinmann, R., Krek, A., and Blaschke, T., 2005. Can online map-based applications improve citizen participation? In: M. Böhler, J. Gamper, W. Polasek and M. Wimmer, eds. Lecture notes in computer science. Heidelberg: Springer, 25-35.

Travis, A. and Mulholland, H., 2011. Online crime maps crash under weight of 18 million hits an hour. The Guardian. Available from: http://www.guardian.co.uk/uk/2011/feb/01/online-crimemaps-power-hands-people [Accessed 8 March 2011].

Unwin, D., 2005. Fiddling on a different planet. Geoforum, 36 (6), 681-684.

Wang, Y.D. and Emurian, H.H., 2005. An overview of online trust: concepts, elements, and implications. Computers in Human Behaviour, 21 (11), 105-125.

Wong, S. and Chua, Y.L., 2001. Data intermediation and beyond: issues for web-based PPGIS. Cartographica, 38 (3\&4), 63-80.

Zimmermann, P., et al., 2003. Affective computing - a rationale for measuring mood with mouse and keyboard. International Journal of Occupational Safety and Ergonomics, 9 (4), 539-551. 


\section{Appendix}

Table A1. Trust guidelines for user interface.

\begin{tabular}{|c|c|c|c|c|}
\hline & Graphic design & Structure design & Content design & $\begin{array}{c}\text { Functionality } \\
\text { design }\end{array}$ \\
\hline $\begin{array}{l}\text { User } \\
\text { interface }\end{array}$ & $\begin{array}{l}\text { 1. The menu should } \\
\text { match popular menu } \\
\text { visualisations } \\
\text { 2. The graphical user } \\
\text { interface elements } \\
\text { should offer } \\
\text { affordance and } \\
\text { should comply with } \\
\text { Internet standards } \\
\text { (e.g. visualisation of } \\
\text { links should match } \\
\text { expected colour } \\
\text { codes and } \\
\text { visualisation } \\
\text { patterns) } \\
\text { 3. The visualisation of } \\
\text { interface design } \\
\text { features should be } \\
\text { consistent } \\
\text { throughout the } \\
\text { Website } \\
\text { 4. Use high-quality } \\
\text { graphics to impart } \\
\text { professionalism }\end{array}$ & $\begin{array}{l}\text { 1. Group the menu } \\
\text { and content in a } \\
\text { logical manner } \\
\text { (information should } \\
\text { be easy to find; the } \\
\text { menu should } \\
\text { effectively } \\
\text { communicate } \\
\text { Website's contents) } \\
\text { 2. Provide hyperlinks } \\
\text { to increase } \\
\text { accessibility of } \\
\text { information from } \\
\text { different pages } \\
\text { 3. Textual information } \\
\text { on different pages } \\
\text { should be grouped } \\
\text { effectively and } \\
\text { should be relevant } \\
\text { to the context } \\
\text { 4. Titles, headings and } \\
\text { subheadings should } \\
\text { be meaningful and } \\
\text { should help with } \\
\text { skipping } \\
\text { paragraphs } \\
\text { (especially if } \\
\text { textual information } \\
\text { is too long) } \\
\text { 5. Provide a site map } \\
\text { 6. Provide a menu } \\
\text { item for the GIS } \\
\text { element }\end{array}$ & $\begin{array}{l}\text { 1. Vocabulary should } \\
\text { be easy to } \\
\text { understand or } \\
\text { should be explained } \\
\text { 2. Explain scientific } \\
\text { terms and provide } \\
\text { interactivity options } \\
\text { (e.g. hyperlinks, } \\
\text { pop-up messages) } \\
\text { so that people can } \\
\text { refer to them easily } \\
\text { 3. Run frequent } \\
\text { updates } \\
\text { 4. Error messages } \\
\text { should be } \\
\text { communicated in } \\
\text { non-technical terms } \\
\text { 5. Support both } \\
\text { domain experts' } \\
\text { and novices' needs } \\
\text { (e.g. in case an } \\
\text { expert user expects } \\
\text { additional } \\
\text { information, } \\
\text { provide external } \\
\text { links previously } \\
\text { inspected for } \\
\text { reliability } \\
\text { purposes) } \\
\text { 6. Provide guidance } \\
\text { and documentation } \\
\text { for system's novice } \\
\text { and expert users }\end{array}$ & $\begin{array}{l}\text { 1. Fix broken } \\
\text { links or } \\
\text { 'Not Found' } \\
\text { pages }\end{array}$ \\
\hline
\end{tabular}

Table A2. Trust guidelines for GIS component.

\begin{tabular}{|c|c|c|c|c|}
\hline & Graphic design & Structure design & Content design & $\begin{array}{c}\text { Functionality } \\
\text { design }\end{array}$ \\
\hline $\begin{array}{l}\text { GIS com- } \\
\text { ponent }\end{array}$ & $\begin{array}{l}\text { 1. Colour combinations } \\
\text { should be effective; } \\
\text { use distinct colours } \\
\text { (e.g. red/blue/green } \\
\text { or alternatively } \\
\text { shades of blue; } \\
\text { consider colour } \\
\text { deficiency) }\end{array}$ & $\begin{array}{l}\text { 1. Always provide a } \\
\text { legend to explain } \\
\text { map features (even } \\
\text { when the map is } \\
\text { considered to be } \\
\text { simple) }\end{array}$ & $\begin{array}{l}\text { 1. Information about } \\
\text { spatial features } \\
\text { should be easy to } \\
\text { access from map } \\
\text { page }\end{array}$ & $\begin{array}{l}\text { 1. Ensure } \\
\text { browser } \\
\text { compatibility }\end{array}$ \\
\hline
\end{tabular}


Table A2. (Continued).

\begin{tabular}{|c|c|c|c|}
\hline Graphic design & Structure design & Content design & $\begin{array}{c}\text { Functionality } \\
\text { design }\end{array}$ \\
\hline $\begin{array}{l}\text { 2. Communicate map } \\
\text { results effectively } \\
\text { (avoid overlapping } \\
\text { symbols; instead use } \\
\text { different colours or } \\
\text { shapes and } \\
\text { transparency levels) } \\
\text { 3. Map size should be } \\
\text { larger than } \\
\text { 400 } \times \text { 600 pixels } \\
\text { 4. Selected objects } \\
\text { should be easy to } \\
\text { identify } \\
\text { 5. Base maps should be } \\
\text { of high quality and } \\
\text { relevant to the } \\
\text { context of the } \\
\text { application } \\
\text { 6. The map results } \\
\text { should stand out } \\
\text { from the base maps } \\
\text { (do not use the } \\
\text { colours of base maps } \\
\text { to visualise } \\
\text { additional } \\
\text { information) } \\
\text { 7. Scales should be } \\
\text { chosen so that each } \\
\text { provides high quality } \\
\text { and useful maps } \\
\text { 8. Legend should be of } \\
\text { high quality and help } \\
\text { interpret the map and } \\
\text { all of its features. } \\
\text { It should be simple } \\
\text { and provide } \\
\text { information of both } \\
\text { map results and base } \\
\text { map features }\end{array}$ & $\begin{array}{l}\text { 2. Legends should } \\
\text { not block the } \\
\text { map } \\
\text { 3. Search box } \\
\text { should be } \\
\text { immediately } \\
\text { visible from map } \\
\text { page (ideally } \\
\text { located next to } \\
\text { the map) }\end{array}$ & $\begin{array}{l}\text { 2. Generalisation } \\
\text { should not lead } \\
\text { users to doubt map } \\
\text { accuracy or make } \\
\text { maps difficult to } \\
\text { read } \\
\text { 3. More than four } \\
\text { scales should be } \\
\text { provided and } \\
\text { should be chosen to } \\
\text { support and provide } \\
\text { meaning to the } \\
\text { tasks } \\
\text { 4. The information on } \\
\text { base maps should } \\
\text { be considered } \\
\text { separately for each } \\
\text { map scale so that } \\
\text { maps are not } \\
\text { cluttered } \\
\text { 5. Provision of } \\
\text { information about } \\
\text { spatial features } \\
\text { should support both } \\
\text { experts' and } \\
\text { novices' needs and } \\
\text { expectations } \\
\text { 6. Information as to } \\
\text { how the maps were } \\
\text { constructed should } \\
\text { be always provided } \\
\text { 7. Provide help and } \\
\text { documentation/ } \\
\text { instructions/or } \\
\text { tutorials about GIS } \\
\text { tasks } \\
\text { 8. Provide } \\
\text { information about } \\
\text { data accuracy } \\
\text { issues (ideally } \\
\text { located below the } \\
\text { map) } \\
\text { Note: Information } \\
\text { about the data, } \\
\text { maps and tasks } \\
\text { should be visible on } \\
\text { the map page (e.g. } \\
\text { information should } \\
\text { be below the map; } \\
\text { links that direct } \\
\text { users to pages } \\
\text { where this } \\
\text { information is } \\
\text { located should be } \\
\text { next to the map) }\end{array}$ & $\begin{array}{l}\text { 2. Map } \\
\text { functionality } \\
\text { should be } \\
\text { consistent (at all } \\
\text { scales) } \\
\text { 3. Map } \\
\text { functionality } \\
\text { should be } \\
\text { unique (do not } \\
\text { provide more } \\
\text { than one } \\
\text { function for the } \\
\text { same task) } \\
\text { 4. An undo or } \\
\text { cancel feature } \\
\text { should be } \\
\text { provided, if the } \\
\text { application } \\
\text { supports } \\
\text { complex tasks } \\
\text { 5. Ensure that map } \\
\text { tools can be } \\
\text { easily } \\
\text { recognised (or } \\
\text { else provide a } \\
\text { tutorial, FAQ } \\
\text { section visible } \\
\text { from the map } \\
\text { page) } \\
\text { 6. Functionality } \\
\text { tools should be } \\
\text { predictable } \\
\text { 7. Provided } \\
\text { functionality } \\
\text { should support } \\
\text { users' needs and } \\
\text { expectations } \\
\end{array}$ \\
\hline
\end{tabular}

